\title{
KAJIAN NILAI-NILAI DASAR KEHIDUPAN PADA SASTRA LISAN TERNATE
}

\section{THE STUDY OF FUNDAMENTAL VALUES OF LIFE IN TERNATE ORAL TRADITION}

\author{
Masayu Gay \\ Prodi Pendidikan Bahasa dan Sastra Indonesia, STKIP Kie Raha Ternate \\ Jalan Raya STKIP, Sasa, Temate Selatan \\ Posel: Masayufm@yahoo.co.id
}

\begin{abstract}
Abstrak
Penelitian ini bertujuan untuk mengungkapkan nilai-nilai dasar kehidupan di sastra lisan Ternate (dola bololo, drum proposisi, dan moro proposisi). Teori yang digunakan sebagai pendekatan untuk menemukan nilai-nilai yang struktural dan hermeneutika. Kedua teori ini digunakan untuk memahami nilai-nilai yang optimal dalam sastra lisan. Metode yang digunakan adalah analisis deskriptif. Hasil penelitian menunjukkan bahwa sastra lisan Ternate, dola bololo: mengandung nilai-nilai dasar kehidupan: (1) kerendahan hati, terutama dalam bahasa; (2) larangan menyakiti orang lain; (3) orang dan kehidupan dunianya (4) perbedaan (pluralisme). Dalil tifa: tentang pentingnya pengetahuan (islam); dan dalil moro: tentang kebersamaan dan kasih sayang, serta manusia dan kematiannya.
\end{abstract}

Kata kunci: nilai-nilai kehidupan, sastra lisan Ternate

\section{Abstract}

This is a descriptive analytical research which aims to reveal the basic values of life in Ternate oral tradition (dola bololo, drums proposition, and Moro proposition). The values are assessed through structural and hermeneutic approach. The results indicate that dolabololo reflects fundamental values of (1) generosity; (2) prohibition against hurting others; (3) The man and his world; (4) pluralism. Dalil tifa reflects Islamism, togetherness, affection, humanity and death.

Keywords: values of life, Ternate oral tradition

\section{Pendahuluan}

Kota Ternate, Maluku Utara memiliki peran dalam sejarah dunia dengan jalur sutranya kaya akan potensi budaya dan karya sastra. Keramahan adalah bukti kalau dahulu masyarakat di Kota Ternate memiliki nilai-nilai dasar fundamental yang sekarang terdapat pada sastra-sastra lisan. Nilai-nilai dasar tersebut menjadi modal dalam kehidupan bermasyarakat. Dinsie dan Taib (2008:62) mengatakan bahwa tanpa disadari para leluhur negeri Moloku Kie Raha telah mewariskan semangat kepada kita akan pentingnya persatuan dan persaudaraan sebagai prasyarat bagi terciptanya pembangunan perdamaian. Menurut Ibrahim (2008:1--2), jika dibaca secara saksama, dola bololo sesungguhnya mengandung banyak kearifan, terutama yang berkaitan dengan bagaima na masyarakat perlu membina kerjasama, membantu sesama, dan menghargai perbedaan sebagai bagian penting dari budaya berpikir dan bertindak poisitif.

Syah (dalam Ahmad, 2014:vii), mengatakan bahwa tradisi lisan (sastra lisan) adalah salah satu bentuk produk budaya daerah yang diciptakan oleh masyarakat masa lalu untuk dipraktikkan 
dalam kehidupan sosial mereka. Hal ini tidak lain karena sastra lisan itu sendiri mengandung nilainilai dasar kehidupan yang sangat bermanfaat dan berarti bagi kehidupan di masa itu, seperti (1) kesantunan, terutama dalam berbahasa; (2) larangan menyakiti orang lalin; (3) manusia dan kehidupan dunianya (4) perbedaan (pluralisme). Dalil tifa: menyangkut pentingnya pengetahuan (islam); dan dalil moro: tentang kebersamaan dan kasih sayang, serta manusia dan kematiannya. Nilai-nilai dasar tersebut mengatur kehidupan dunia dan akhirat.

Nilai-nilai ini perlu diketahui masyarakat, khususnya yang berdomisili di Kota Ternate. Sebab belakangan ini sering terjadi masalah sosial, seperti perkelahian antar pemuda, perbedaan politik yang memicu sukuisme dan pertikaian, bahkan tindakan yang menyimpang dari norma dan agama. Masalah-masalah ini mungkin akan tetap terjadi, mengingat Kota Ternate masyarakatnya telah pluralitas (pribumi dan pendatang). Kondisi ini harus diantisipasi, salah satunya adalah dengan menghidupkan kembali, serta terus menunjukkan nilai-nilai dasar kehidupan sastra lisan sebagai produk budaya para leluhur yang harmonis dan religius. Mengingat fungsi sastra itu sendiri memberikan kesadaran tentang kebenaran-kebenaran hidup, kehidupan masa lampau, adat istiadat, sekaligus hiburan. Hiburan ini adalah jenis hiburan intelektual dan spiritual.

Merujuk pada dasar pikir di atas, fokus masalah penelitian, yakni bentuk-bentuk nilai dasar kehidupan pada sastra lisan Ternate pada ketegori manusia dalam kehidupannya (hubungan menusia dengan manusia), serta kategori manusia dan kehidupan religiusitasnya. Tujuannya untuk mendeskripsikan bentukbentuk nilai kehidupan yang terkandung dalam sastra lisan tersebut, baik kehidupan dunia maupun akhirat, serta melindungi sastra lisan tersebut dari ancaman kepunahan akibat modernisasi. Penulisan dibatasi hanya pada dola bololo, dalil moro, dan dalil tifa dengan nilainilai dasarnya, seperti: (1) kesantunan, terutama dalam berbahasa; (2) larangan menyakiti orang lalin; (3) manusia dan kehidupan dunianya (4) perbedaan (pluralisme). Dalil tifa: menyangkut pentingnya pengetahuan (islam); dan dalil moro: tentang kebersamaan dan kasih sayang, serta manusia dan kematiannya. Nilai-nilai dasar kehidupan ini merupakan produk budaya leluhur masyarakat Ternate yang sangat relevan diaplikasikan pada kondisi saat ini.

\section{Kerangka Teori}

Sastra lisan adalah salah satu jenis karya sastra yang terkadang sulit untuk dipahami. Kesulitan muncul dalam memahami nilai atau makna pada bahasa, sehingga bahasa yang digunakan pada karya sastra yang merupakan tanda harus ditafsirkan dengan pendekatan teori dan metode yang tepat. Dengan demikian, untuk memahami nilai-nilai dasar kehidupan sastra lisan Ternate digunakan pendekatan teori strukturalisme dan hermeneutik. Beberapa teori pendukung lain digunakan sebagai sumber referensi, kerangka pijak penulisan ini.

\subsection{Pengertian Nilai}

Berdasarkan KBBI (2008:936), nilai diartikan sebagai sifat-sifat (hal-hal) yang penting atau berguna bagi manusia. Nilai berasal dari bahasa Inggris yaitu value atau harga. Menurut Bariqoh (2015:260), nilai akan selalu muncul ketika individu mengadakan hubungan sosial dengan masyarakat atau dengan individu lainnya. Sesuatu itu mempunyai nilai karena ia mempunyai harga, atau sesuatu itu mempunyai harga karena ia mempunyai nilai. Nilai yang dimaksud dalam hal ini adalah proses menimbang atau menaksir, yaitu kegiatan manusia yang menghubungkan sesuatu dengan sesuatu untuk selanjutnya diambil keputusan.

\subsection{Sastra Lisan}

Sastra adalah sebuah produk budaya, kreasi pengarang yang hidup dan terkait dengan tata kehidupan masyarakatnya (Noor, 2011:23). Menurut Zulela (2012:20), sastra mengungkapkan pengalaman manusia agar 
manusia lain dapat mengambil pelajaran dari pengalaman itu dan hidup manusia akan lebih baik.

Pembicaraan mengenai sastra, khususnya sastra lisan saat ini mulai mengemuka seiring dengan munculnya konsepsi tentang kearifan lokal (local wisdom) (Ahmadi, 2010:17) yang berusaha menggali dunia lokal agar tidak hilang dan tergerus oleh arus modernisme yang pragmatis.

Sastra lisan dianggap sebagai bentuk sastra pertama. Karya sastra telah tercipta jauh sebelum nenek moyang kita mengenal aksara untuk menuliskan kembali apa yang telah mereka ceritakan, sehingga penyebarannya dilakukan secara lisan atau oral. Sastra lisan pada hakikatnya ialah sastra yang diperdengarkan (Bartlett, 1965:244-245).

\subsection{Sastra Lisan Temate}

Sastra lisan Ternate adalah jenis sastra yang berada di tengah-tengah masyarakat yang berbentuk lisan. Syah (dalam Ahmad, 2014:vii) mengungkapkan bahwa sastra lisan Ternate, sebagai produk budaya dan tradisi masyarakat Ternate, sesungguhnya memiliki arti tersendiri untuk kehidupan masa kini, meskipun ruang penggunaannya tidak seluas masa lalu. Salah satu arti dan manfaat itu adalah sastra lisan mengungkapkan atau menjadi cermin kehidupan kultural masyarakat lama dengan norma-norma adat dan tradisi yang kuat dipegang, yang tentu dapat menunjukkan identitas sosial-budaya kita yang sesungguhnya.

Sastra lisan di Ternate berfungsi sebagai pembentuk watak manusia yang baik, sebagai alat kontrol masyarakat, sebagai alat komunikasi untuk menjalin hubungan kekeluargaan atau kekerabatan, dan sebagai alat penghibur dan juga berfungsi sebagai alat untuk mempertahankan kecermatan berbahasa.

Ahmad (2014:7) menggolongkan sembilan sastra lisan yang dimiliki masyarakat Ternate menjadi sastra lisan berbentuk bukan cerita dan berbentuk cerita, di antaranya sebagai berikut.

\begin{tabular}{l|l}
\hline $\begin{array}{c}\text { Berbentuk bukan } \\
\text { Cerita }\end{array}$ & \multicolumn{1}{c}{$\begin{array}{c}\text { Berbentuk Cerita } \\
\text { atau Jarita }\end{array}$} \\
\hline Dola bololo & Mitos (mite) \\
\hline Dalil moro & Legenda \\
\hline Dalil tifa & Dongeng \\
\hline Pandara (pantun) & Fabel \\
\hline Mantra & Sage \\
\hline Rorasa & \\
\hline Cum-cum & \\
\hline Moro se saluma & \\
\hline
\end{tabular}

Sumber: Ahmad (2014:7).

Dola bololo adalah suatu ungkapan tradisional masyarakat Ternate yang memiliki pesan dan ajaran tertentu dan pengungkapannya tanpa menyinggung perasaan orang yang menjadi tujuan pengungkapan (Ahmad, 2014:10). Dola bololo adalah pantun yang digunakan masyarakat, dan dijadikan sebagai sumber norma yang mengatur tata kehidupan masyarakat. Namun, pantun yang dimaksud bukanlah pantun tanpa makna/nilai. Bahkan terdapat nilai-nilai kehidupan yang berfungsi mengatur manusia dengan manusia, bahkan manusia dengan penciptanya.

Dalil moro adalah salah satu bentuk puisi yang hampir memiliki kesamaan dengan pantun. Perbedaan terletak pada hubungan semantisnya. Dalil moro secara umum terdiri dari empat baris, dan memiliki hubungan antar baris tersebut yang membentuk satu kesatuan nilai/makna. Dalil tifa memiliki kesamaan dengan dola bololo dan dalil moro. Perbedaanya terletak pada banyaknya laris yang terdapat pada dalil tifa antara lima sampai enam laris, pengucapannya diiringi dengan musik tifa.

\subsection{Teori Strukturalisme}

Menurut Ratna (2009:91) (dalam Yulianto, 2015:77), bahwa secara definitif strukturalis me berarti paham mengenai unsur-unsur, yaitu struktur itu sendiri dengan mekanisme 
antarhubungannya. Disatu pihak, hubungan antarunsur yang satu dan unsur lainnya, di lain pihak hubungan antarunsur dengan totalitasnya.

Berdasarkan Kamus Istilah Sastra (2007:194), strukturalisme adalah metode yang menganggap objek studinya bukan hanya sekumpulan unsur yang terpisah-pisah, melainkan sebagai suatu gabungan unsur yang berhubungan satu sama lain, sehingga yang satu bergantung pada yang lain. Kajian struktural diikuti pula dengan kajian semiotik.

Selden (1986:6) (dalam Ratna, 2007:97), menganggap strukturalisme dan semiotik termasuk ke dalam ilmu yang sama. Untuk menemukan makna suatu karya, analisis strukturalisme mesti dilanjutkan dengan analisis semiotik. Dalam pengertian yang lebih luas, sebagai teori, semiotika berarti studi sistematis mengenai produksi dan interpretasi tanda.

\subsection{Teori Hermeneutik}

Hermeneutik merupakan metode yang paling sering digunakan dalam penelitian karya sastra. Hermeneutik modern berkembang pada abad ke19 melalui gagasan Schleiermacher. Dalam sastra hermeneutik disejajarkan dengan interprertasi, pemahaman, verstehen, dan retroaktif (Ratna, 2007:45).

Secara etimologis hermeneutika berasal dari kata hermeneuein, bahasa Yunani yang berarti menafsirkan atau menginterpretasikan. Karya sastra perlu ditafsirkan sebab di satu pihak karya sastra terdiri atas bahasa, dipihak lain, di dalam bahasa sangat banyak makna yang tersembunyi, atau dengan sengaja disembunyikan. Metode hermeneutik tidak mencari nilai atau makna yang benar, melainkan makna yang paling optimal.

\section{Metode}

Pendekatan yang digunakan untuk menemukan nilai-nilai kehidupan pada sastra lisan Ternate adalah struktural dan hermeneutik. Kedua teori ini digunakan untuk menemukan nilai-nilai yang optimal pada sastra lisan Ternate. Nilai-nilai tersebut berupa manusia dan kehidupannya, serta manusia dan religiusitasnya.

Metode yang digunakan adalah deskriptif analisis. Alfarisi (2015:127), metode deskriptif analis is merupakan metode penguraian. Ratna, 2007:53, hal ini disesuaikan cara mendeskripsikan fakta-fakta yang kemudian disusul dengan analisis. Fakta-fakta berupa ungkapan-ungkapan pada sastra lisan dideskripsikan, kemudian disusulkan dengan analis is nilai-nilai kehidupannya.

Tahap-tahap analisis data mengikuti prosedur berikut: (1) pengumpulan data, baik data ungkapan langsung informan maupun hasil tinjauan pustaka, (2) menafsirkan atau menginterpretasi, (3) mengklasifikasikan bentuk nilai-nilai dasar sastra lisan, dan (4) merumuskan hasil penelitian dan penarikan kesimpulan.

\section{Pembahasan}

Kajian struktural melihat teks sastra sebagai suatu komponen atau unsur-unsur yang berhubungan atau saling terkait antar satu dengan yang lain, serta kesemestaannya yang melingkupinya. Selanjutnya, sesuai metode hermeneutik maka simbol-simbol bahasa dalam karya sastra harus diinterpretasi atau ditafsirkan untuk mendapatkan makna tersesurat dan tersiratnya.

\subsection{Nilai-nilai Dasar Kehidupan pada Dola Bololo}

\subsubsection{Kesantunan Berbahasa}

Bahasa adalah sarana penghubung antar manusia yang satu dengan yang lain. Dengan kata lain, bahasa merupakan media atau alat berkomunikasi. Manusia berbahasa menggunakan kata-kata. Oleh karena itu, pemilihan kata yang tepat dan sesuai konteks sangat dianjurkan. Hal ini mengarah pada dua hal, yakni agar berhasa dapat dipahami dan berbahasa tidak menyinggung perasaan pendengar.

Menurut Ahmad dan Henri (2015:23), pemilihan kata bukan sekedar kegiatan memilih kata yang tepat, melainkan juga memilih kata 
yang cocok. Cocok dalam hal ini berarti sesuai dengan konteks di mana kita berada, dengan siapa kita berbicara, dan maknanya tidak bertentangan dengan nilai rasa masyarakat pemakainya.

Kategori penggunaan bahasa yang tepat (santun atau halus) dianjurkan pada satra lisan Ternate. Anjuran pemakaian kata halus terdapat pada dola bololo yang merupakan sepotong ungkapan yang terdiri atas dua bait.

\section{Eli-eli susunyinga demo ma dero afa, mara cobo sala demo kanang.}

Ingat-ingatlah kata yang tepat, jangan sampai salah memilih kata.

Kajian struktural dan hermeneutik terhadap makna dola bololo diketahui bahwa jenis sastra lisan ini berisi pernyataan perasaan dan pendapat seseorang dalam bentuk sindiran dan tamsilan dan merupakan ciri kebijakan seseorang melalui peribahasa, sehingga tidak menyinggung perasaan. Sindiran dan peribahasa tergolong tuturan tak langsung, yang dianggap memiliki kesantunan yang tinggi dibandingkan tuturan langsung.

Anjuran menggunakan kata yang tepat pada ungkapan di atas dapat ditafsirkan atau dinterpretasikan sebagai kata-kata yang tepat atau kata-kata halus dan sopan (tidak mengandung makian). Kata-kata halus dan tidak makian akan menimbulkan keharmonisan dan kasih sayang antar pembicara dan pendengar. Nilai kesantunan berbahasa pada dola bololo merupakan gambaran atau cerminan nilai kehidupan masyarakat leluhur Ternate sebagai kualitas totalitas dan fakta antarhubungan nilai-nilai tersebut dengan prilaku kehidupannya melalui medium bahasa.

\subsubsection{Manusia dan Kehidupan Dunia}

Dunia tempat menusia berpijak dengan segala keindahannya hanyalah sementara. Keindahan pada dunia ini akan hilang atau musnah jika telah datangnya masalah. Nilai kehidupan dunia dan segala keindahannya dijelaskan secara gamblang pada ungkapan di bawah.
Dunya ne doka nga soya, waktu wange dahe bungan muraha ma bou sai.

(dunia ini ibarat kembang, waktu diterpa panas kembangnya layu, wanginya pun melayang).

Secara umum kata "bunga" sering dikonotasikan sebagai sesuatu yang indah, harum. Konotasi ini sudah menjadi konvensi umum. Ketegori ini dunia yang merupakan tempat kehidupan menusia disimbolkan dengan kembang. Dalam KBBI (2008:222), "kembang" berhubungan dengan bunga (bagian tumbuhan yang akan menjadi buah), biasanya elok warnanya dan harum baunya; kembang.

Makna dunya ne doka nga soya "dunia ini sangatlah indah". Hal yang menyebabkan "dunia indah", misalnya hidup bergelimang harta atau keindahan lain yang dapat dilihat, dirasa, dan didengar. Simbol "kembang" dihubungkan dengan kata wange (panas). Simbol wange (panas) dimaknai sebagai masalah yang ditimbulkan oleh perbuatan manusia sebagai penyebab tak berguna (layu) atau hilang tak berarah (melayang) dunia dan keindahan itu.

Teks sastra lisan di atas, menyiratkan keindahan dunia dan masalah yang ditimbulkan manusia. Makna ini dipertegas pula dengan ungkapan sastra di bawah.

Dunia i ira ua, ngone fo ma gulaha.

(Dunia ini tidak buruk, kecuali disebabkan perilaku manusia).

Dunia tidaklah buruk, dunia ini indah atau bagus dan selamanya akan tetap indah. Keindahan dunia dijelaskan Allah SWT dalam (Qur'an: Ar-rum:41) "Telah nampak kerusakan di darat dan di laut disebabkan karena perbuatan tangan manusi, supaya Allah merasakan kepada mereka sebahagian dari (akibat) perbuatan mereka, agar mereka kembali (ke jalan yang benar)".

Prilaku atau perbuatan manusia yang buruk dapat interpretasikan perbuatan melanggar ajaran 
agama berupa pengrusakan, baik di darat (kerusakan ekologi, kerusakan tatanan kehidupan) maupun di laut (kerusakan pantai dan biota laut). Dengan demikian, sastra lisan tersebut mengandung anjuran dan mengatur secara tegas bagaimana seharusnya manusia hidup di alam semesta ini.

Makna universal, termasuk pada kategori manusia dan kehidupannya tersirat juga pada teks di bawah. Simbol cahaya secara harfiah dapat diinterpretasikan sebagai sinar atau terang.

Ure fo mara ai laha kara sum si kado ngo Ure fo mara ai ira sung si gado ngo ua

(Benda yang berwarna selain putih, mengenai cahaya akan pudar)

(Tapi kalau warna putih tidak akan pudar)

Kata cahaya disandingkan dengan kata pudar yang menunjukkan adanya keterkaitan sebab akibat. Interpretasi makna universal muncul dari teks ini adalah tentang sikap dan prilaku manusia. Warna putih dikonotasikan sebagai 'kesucian, bersih' bebas dari kotoran yang merupakan konvensi masyarakat umum. Makna optimal yang dapat diinterpretasikan adalah jika dalam kehidupannya manusia dapat menjaga prilakunya dengan baik maka akan berdampak baik pada dirinya. Sebaliknya, jika ia tidak dapat menjaga prilaku dan perbuatannya maka berakibat buruk padanya (pudar).

\subsubsection{Larangan Menyakiti Orang Lain}

Kategori ini memusatkan perhatian pada manusia yang menyangkut sifat keadaan yang abstrak. Sesuatu yang tidak dapat langsung dihayati oleh indra manusia, tetapi sangat dianjurkan untuk tidak tersakiti.

Nilai dasar sastra lisan Ternate pada kategori ini berupa kalimat yang terdiri dari dua frasa. Frasa pertama gogola nyinga afa mengandung makna lugas, sedangkan frasa kedua bermakna metafor nyinga ma bubang nyinga. Berikut di bawah transkripsinya.
Gogola nyinga afa, nyinga ma bubang nyinga.

(Janganlah sakiti hati, karena hati terbayar hati).

Frasa nyinga ma bubang nyinga mengandung metafor, sehingga untuk melacak maknanya peneliti menafsirkan simbol nyinga ma bubang nyinga. Secara harfiah hati tidak dapat dibayar. Makna penggalan di atas dimaknai dalam bentuk kalimat, sehingga makna optimalnya adalah menyakiti hati orang lain sama halnya dengan menyakiti diri sendiri. Simbol ini menginterpretasikan bahwa menyakiti hati orang lain pasti akan dibalas orang lain. Perilaku tidak menyakiti bahkan melukai hati dan perasaan orang lain dianjurkan, diwariskan secara temurun oleh nenek moyang orang Ternate sebagai nilainilai dasar kehidupan bagi generasi hari ini, besok, dan akan datang.

\subsubsection{Perbedaan (pluralisme)}

Perbedaan terjadi dalam berbagai aspek, baik agama, suku, maupun kebutuhan. Hal ini disebabkan pandangan hidup, keyakinan, cara pikir, dan tujuan hidup yang berbeda antara individu satu dengan yang lain, tetapi perbedaan itu merupakan hal lumrah. Kategori perbedaan pada sastra lisan tersebut melahirkan keuniversalan makna perbedaan, yang secara gamblang didalilkan pada sastra lisan Ternate berikut.

Hele fo nyonyomo-nyonyomo, ma nyonyohi ena bato.

(Meskipun berbeda arah, tujuan kita satu).

Nilai dasar kehidupan pada ungkapan tersebut adalah bahwa masyarakat leluhur menghargai dan menerima perbedaan dalam kehidupan. Saling menghargai perbedaanperbedaan yang ada. Perbedaan pada hakikatnya hanya pada tujuan hidup maisng-masing individu. Makna sastra lisan di atas, kurang lebih 
sama dengan dasar negara kita dengan simbolnya Bhinneka Tunggal Ika 'berbeda-beda tetap satu'.

\subsection{Nilai Dasar Kehidupan Dalil Tifa dan Dalil Moro}

\section{Dalil Tifa: Pentingnya Ilmu (Islam)}

Dalil tifa mengandung nilai-nilai dasar kehidupan tentang pentingnya ilmu bagi penyeimbang kehidupan dunia dan akhirat. Sastra lisan ini menganjurkan agar setiap orang harus berilmu (agama) yang cukup. Untuk memeroleh ilmu, setiap orang harus memaksimalkan akal dan pikirannya. Hal ini dapat dilihat pada dalil berikut.

\section{Matubu kie graha}

(Puncaknya empat gunung)

Lobi yo fati sio gamam

(Kabut menutup aduhai gelap)

Ahu moju fo madike

(Selagi hidup kita mencari)

Guru-guru yo nga demo

(Guru-guru punya ucapan)

Bala wasu marari pada

(Untuk menjadi pelitaku)

Ngama ri moi kari nonako

(Sebuah bintang menjadi tanda)

Simbol kabut ditafsirkan sebagai awan tebal yang menyelimuti suatu benda (gunung). Simbol tersebut dihubungkan dengan gelap (gamam) yang dalam bahasa Ternate "sangat gelap, gelap sekali', sehingga tidak terlihat. Guru adalah orang yang memiliki banyak pengetahuan. Jadi, ucapan guru akan menjadi petunjuk. Hal ini dapat dilihat pada simbol ucapan yang dikonsepkan dengan pelita (benda yang dapat memberikan penerangan) dan bintang benda angkasa yang juga bercahaya. Makna optimal sebagai nilai kehidupan pada sastra tersebut adalah bahwa manusia hidup harus mencari ilmu agar dapat membekali dirinya. Ilmu tersebut akan menjadi penerang baginya sebab ilmu adalah cahaya.

Beberapa simbol yang berkaitan dengan kategori nilai-nilai dasar tersebut, yakni (1) perahu, (2) kemudi, dan (3) lautan. Perahu dikonsepkan dengan iman, kemudi dikonsepkan dengan islam, lautan dikonsepkan dengan Ilahi (Ilahi: bersifat ketuhanan).

Perahu dapat diinterpretasikan sebagai benda yang sering dinaiki untuk bepergian di suatu tempat, kemudi adalah alat pengatur pelayaran, iman adalah keyakinan, dan lautan adalah laut yang luas sekali; samudra yang sifatnya tidak selalu tenang (bergelombang).

Fo wito nga oti iman

(Kita dorong perahu iman)

Nga ngungudi islam

(Dengan kemudi islam)

Fo tola ngolo kadim

(Seberangi lautan ilahi)

Kadim ma ati ruma

(Perahu ilahi hancur di laut hamba)

Toma bahari ma ngolo

(Bukan milik hambanya)

Bahari nga due ua kadim nga dua

(Kepunyaan ilahi jua)

Namun, di sisi lain ada kalimat yang menyatakan perahu Ilahi hancur di laut hamba. Hal tersebut dapat diinterpretasikan bahwa untuk mengetahui kebesaran dan kekuasaan Ilahi harus pengetahuan tentang iman dan islam yang cukup, agar pencaharian membawa manusia pada pemahaman yang tidak menyalahi atau salah memahami (hancur di laut hamba) tentang keIlahi-an itu sendiri. Sesesuatu (iman dan islam) untuk menyeberangi lautan Ilahi bukan milik manusia, melainkan Ilahi.

\subsubsection{Dalil Moro}

\subsubsection{Kebersamaan dan Kasih Sayang}

Simbol pala (gosora) dan cengkeh (bualawa) dipergunakan dalam ungkapan dalil moro. Diketahui bahwa kedua tumbuhan ini sangat berbeda dan sulit untuk disamakan ciri dan bentuknya. Kalau secara harfiah kedua pohon ini adalah jenis pohon yang menghasilkan buah. Berikut adalah ungkapan dalil moro.

Ino foma katinyinga

(Mari kita menyatukan hati) 
Doka gosora se bualawa

(Seperti pala dengan cengkeh)

Om doro foma kumote

(Matang dan gugur bersama-sama)

Fokau gogoru fomako udara

(Saling mengasihi dan saling menyayangi)

Simbol pala (gosora) dengan fulinya, cengkeh (bualawa) dengan bunganya. Kedua buah ini matang dan jatuh sama-sama. Diinterpretasikan bahwa perbedaan harus disatukan, saling mengasihi, dan menyayangi.

\subsubsection{Manusia dan Kematiannya}

Jika ungkapan tersebut di atas mengand ung nilainilai dasar kehidupan manusia dengan manusia, maka ungkapan di bawah mengandung nilai dasar kehidupan antara manusia dengan manusia dan manusia dengan sang penciptanya.

\section{Sone daka rika-rika fodumaha mabubudo}

Sone daka rika-rika fodumaha ma rukun koa Sone daka rika-rika fadumaha ma ake raha Sone daka rika-rika sala ngone manusia

(Orang yang sudah meninggal harus secepatnya dikuburkan)

(Orang yang sudah meninggal mengapa harus ditunda pemakamannya)

(Air empat piring untuk dimandikan sudah siap)

(Kubur terlambat mayat tersiksa, salahnya manusia)

Makna secara harfiah dan lugas, tetapi membutuhkan interpretasi di luar bangun tesk dapat dilihat pada ungkapan di atas. Ungkapan yang mengandung nilai-nilai kehidupan dunia dan akhirat bagi masyarakat yang sakral dan kuat. Jika dikaji secara struktural maupun hermenutik, ungkapan di atas dapat diketahui bahwa orang (manusia) yang telah meninggal harus secepatnya dikuburkan, jika kain kafannya sudah siap dan sudah dimandikan. Semakin lama mayat dibiarkan, maka jasadnya tersiksa rika-rika sala ngone manusia dan itu kesalahan manusia.

\section{Kesimpulan}

Berdasarkan pembahasan disimpulkan bahwa ungkapan-ungkapan sindiran (tak langsung) tidak dapat dilepaskan dalam penciptaan sastra yang dapat mewakili ruang persepsi manusia. Sastra lisan Ternate, dola bololo mengandung nilai, yakni (1) kesantunan, terutama dalam berbahasa; (2) larangan menyakiti orang lalin; (3) manusia dan kehidupan dunianya (4) perbedaan (pluralisme). Dalil tifa: menyangkut pentingnya pengetahuan (islam); dan dalil moro: tentang kebersamaan dan kasih sayang, serta manusia dan kematiannya. Nilai-nilai sastra lisan tersebut diungkapan secara metaforis untuk menggambarkan sesuatu yang konkrit untuk tujuan yang abstrak atau sebaliknya dengan lambang-lambang yang konkret.

\section{Daftar Pustaka}

Ahmad dan Hendri. 2015. Mudah Menguasai Bahasa Indonesia. Yrama Widya: Bandung.

Ahmad, Mahdi. 2014. Sastra Lisan Ternate. Depok: Yayasan Danau Indonesia.

Alfarisi, A. B. T. 2015. Ekpresi Metaforis dalam Puisi Mardi Luhung. Jurnal Bebasan. Vol. 2 (2): 127.

Bartlet, F.C. (1965). "Some Experiment on the Introduction of the Folklore". Dalam: A Dundes (ed). The Study of Folklore. Englewood, N.J.: Prentice Hall. 243-258.

Bariqoh, A. 2015. Ekranasi Film Biopic: Penanaman Nilai Semboyan "Jas Merah" sebagai Usaha Pembentukan Karakter Mahasiswa STKIP PGRI Sampang. Prosiding Seminar International Riksa Bahasa IX. 26 November 2015, Bandung, Indonesia. Hal. 260.

Dinsie, Amas dan Thaib, Rinto. 2008. Ternate: Sejarah, Kebudayaan, dan Pembangunan Perdamaian. LeKRa-MKR: Maloku Kie Raha.

Ibrahim, Gufran A. 2009. Dolabololo: Budaya Berpikir Positif Masyarakat Ternate. Makalah dalam bentuk Pdf. 
Tim Penyusun. 2007. Kamus Istilah Sastra. Balai Pustaka: Jakarta.

Tim Penyusun. 2008. Kamus Besar Bahasa Indonesia: Edisi Ke-IV. PT Gramedia: Jakarta.

Majid, Bakhtiar. 2009. "Revitalisasi Tradisi Sastra Lisan Dola Bololo dalam Masyarakat Kesultanan Ternate: Sebuah Kajian Budaya". Tesis Program Studi Kajian Budaya, Universitas Udayana, Bali.

Noor, M. Rohinah. 2011. Pendidikan Karakter Berbasis Sastra. Jogjakarta: Ar-Ruzz Media.

Ratna N. Kutha. 2004. Teori, Metode, dan Teknik Penelitian Sastra: Cetakan I. Pustaka Pelajar: Yigyakarta.

- 2007. Teori, Metode, dan Teknik Penelitian Sastra: Cetakan III. Pustaka Pelajar: Yogyakarta.

Yulianto, A. 2015. Analisis Intertekstual Puisi "Tangisan Batu" dan "Air Mata Legenda" Karya Abdurrahman El Husainy. Jurnal Sirok Bastra. Vol. 3 (1): 75-81.

Zulela. 2012. Pembelajaran Bahasa Indonesia:Apresiasi Sastra di Sekolah Dasar. Bandung: PT Remaja Rosdakarya. 